\title{
EVOLUCIÓN DE LA CONCENTRACIÓN DE SÓLIDOS ÚTILES EN LECHE DE TAMBOS DEL NE DE LA PROVINCIA DE SANTA FE: PERÍODO 2003-2013
}

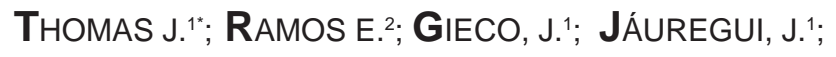 \\ Badino, O..$^{1 ;}$ LeVA P. $^{1}$ \& Toffoli G. ${ }^{1}$
}

\begin{abstract}
RESUMEN
El noreste de la provincia de Santa Fe, con algunas restricciones edafo-climáticas, presenta ventajas respecto a otras zonas del país, por su proximidad a grandes empresas procesadoras de productos lácteos. El objetivo, fue estudiar la evolución de la concentración de sólidos útiles (SU) en tambos de la región NE de Santa Fe; departamentos: San Justo, Vera, Gral. Obligado, Norte de San Javier, durante el período (2003-2013). Se solicitó a las industrias lácteas, promedios mensuales de porcentaje de Materia Grasa (MG) y proteína (PT) en leche. Se realizó un análisis estadístico de las variables mediante ANOVA y test a posteriori de comparaciones múltiples (test de Tukey), entre cada departamento. Considerando los valores informados al inicio del período, existió un incremento de la concentración de SU en la leche producida en los tambos de la región, evidenciado en el aumento del \% PT en los últimos años. Se alcanzaron valores similares a la región pampeana. Palabras claves: leche bovina, sólidos útiles, Noreste de Santa Fe.
\end{abstract}

\section{SUMMARY}

\section{Evolution of the concentration of milk solids on dairy farms from NE of Santa Fe Province.}

North-Eastern of Santa Fe, a region characterized by soil and climate constraints, appears to have advantages over other regions of Argentina because of its proximity to large dairy companies. The objective was to determine the evolution of the concentration of milk solids (MS) from NE of Santa Fe (San Justo, Vera, Gral. Obligado, North of San Javier) from 2003 to 2013. Data of monthly average percentage of milk fat $(\% \mathrm{MF})$ and milk protein $(\% \mathrm{TP})$ was requested from the dairy industry.

1.- Facultad de Ciencias Agrarias, UNL. Kreder 2805. (3080) Eperanza, provincia de Santa Fe. *Email: jthomas@fca.unl.edu.ar

2.- Instituto Nacional de Tecnología Industrial (INTI) Lácteo. (2300) Rafaela, provincia de Santa Fe.

Manuscrito recibido el $1^{\circ}$ de octubre de 2014 y aceptado para su publicación el $1^{\circ}$ de diciembre de 2014. 


\section{J. Thomas et al.}

The supplied data was processed, statistical analysis (ANOVA) for multiple comparisons within each department was performed, and the variables (Fat and protein) were tested (Tukey test). Considering the values informed at the beginning of the period, there was an increase in the concentration of MS. in milk produced on dairy farms in the region, as evidenced by the increase in \% PT in recent years. Similar values to the Pampas region were achieved.

Key words: milk solids, North East of Santa Fe Province.

\section{INTRODUCCIÓN}

La producción de leche en Argentina se ha desarrollado principalmente en la región pampeana (área geográfica situada en el centro-este de Argentina), debido a la disponibilidad de recursos naturales aptos para esta explotación, a la mayor densidad de asentamientos urbanos y a la cercanía a los principales puertos de salida de las exportaciones.

Laproduccióndeleche, sutransformación industrial y su distribución, conforman uno de los complejos agroalimentarios más dinámicos del país. Tiene importancia estratégica, $y$ es en gran medida, responsable del desarrollo económico y social de numerosas economías zonales y regionales por su impacto sobre la generación directa e indirecta de empleo.

En la provincia de Santa Fe la actividad láctea es significativamente importante, tanto a nivel del eslabón primario como del industrial. Integra una de las cuencas lecheras más importantes del país, posee la mayor concentración de tambos (34\%; $\mathrm{n}=3.693$ de tambos), y de vacas (32\%; $\mathrm{n}=503.154)$, de Argentina (11). Por sus características geográficas y climáticas, la lechería se ha localizado fundamentalmente en el centro y sur de la provincia, aunque la actividad tambera se extiende prácticamente en toda su extensión. La Cuenca Central Santafesina, concentra el $78 \%$ de los tambos y el $76,6 \%$ de las vacas de la provincia (Figura I).

En base a la diferenciación y descripción de zonas agroeconómicas homogéneas realizada en el marco del Proyecto RIAN - Red de Información Agroeconómica Nacional (6), y considerando los departamentos del NE de Santa Fe: San Justo; Vera; Gral. Obligado y San Javier; pueden diferenciarse, en esta región, las siguientes zonas homogéneas: departamento San Justo; Calchaquí (Vera); Reconquista (Gral. Obligado), y San Javier. Según Cabrera (2), este sector se localiza en la provincia fitogeográfica chaqueña y presenta clima de transición entre el templado y el subtropical (Fig. 2).

$\mathrm{La}$ región Norte de Santa $\mathrm{Fe}$, y con referencia a los departamentos mencionados, presenta restricciones edafoclimáticas para la producción lechera. Una característica climática importante de esta región para la producción ganadera, es la elevada cantidad de vapor de agua en la atmosfera ( 72 a $80 \%$ en el primer trimestre). El índice de temperatura y humedad (ITH) es muy utilizado en lechería para determinar umbrales de confort $(<72)$ y disconfort para el ganado $(>72)$. El número de días con ITH $>72$ en la provincia varía

98 | Revista FAVE - Ciencias Agrarias 13 (1 - 2) 2014 